\title{
Induction of apoptosis by Galectin-9 in liver metastatic cancer cells: In vitro study
}

\author{
TOMOKO TADOKORO ${ }^{1}$, SHINTARO FUJIHARA ${ }^{1}$, TAIGA CHIYO $^{1}$, KYOKO OURA $^{1}$, ERI SAMUKAWA ${ }^{1}$, \\ YOSHIMI YAMANA ${ }^{1}$, KOJI FUJITA ${ }^{1}$, SHIMA MIMURA ${ }^{1}$, TEPPEI SAKAMOTO ${ }^{1}$, TAKAKO NOMURA ${ }^{1}$, \\ JOJI TANI $^{1}$, HIROHITO YONEYAMA ${ }^{1}$, ASAHIRO MORISHITA ${ }^{1}$, TAKASHI HIMOTO ${ }^{1}$, \\ HISAKAZU IWAMA $^{2}$, TOSHIRO NIKI ${ }^{3}$, MITSUOMI HIRASHIMA ${ }^{3}$ and TSUTOMU MASAKI ${ }^{1}$ \\ ${ }^{1}$ Department of Gastroenterology and Neurology, ${ }^{2}$ Life Science Research Center, and \\ ${ }^{3}$ Department of Immunology and Immunopathology, Kagawa University, Takamatsu, Kagawa, Japan
}

Received January 14, 2017; Accepted June 1, 2017

DOI: 10.3892/ijo.2017.4053

\begin{abstract}
Liver metastasis from gastrointestinal cancer defines a patient's prognosis. Despite medical developments, pancreatic cancer with liver metastasis confers a very poor prognosis. Galectin-9 (Gal-9) is a tandem-repeat-type galectin that has recently been demonstrated to exert antitumor effects on various types of cancer cells by inducing apoptosis. However, the apoptotic pathway of Gal-9 in solid tumors is unclear. The aim of the present study was to evaluate the effects of Gal-9 on human liver metastasis from pancreatic cancer. Gal-9 suppressed cell proliferation in metastatic liver cancer cell lines derived from pancreatic cancer (KMP2, KMP7, and KMP8) and increased the levels of caspase-cleaved keratin 18 and fluorescein isothiocyanate (FITC)-conjugated Annexin V. Furthermore, expression of apoptosis-related molecules such as caspase-7, cleaved caspase-3, cleaved PARP, cytochrome $c$, Smac/Diablo and HtrA2/Omi was enhanced. However, Gal-9 did not affect expression of various cell cycle-related proteins. The microRNA (miRNA) expression profile was markedly altered by Gal-9, and various miRNAs might contribute to tumor growth suppression. Our data reveal that Gal-9 suppresses the growth of liver metastasis, possibly by inducing apoptosis through a mechanism involving mitochondria and changes in miRNA expression. Thus, Gal-9 might serve as a therapeutic agent for the treatment of liver metastasis from pancreatic cancer.
\end{abstract}

Correspondence to: Dr Tsutomu Masaki, Department of Gastroenterology and Neurology, Kagawa University School of Medicine/ Graduate School of Medicine, 1750-1 Ikenobe, Miki-cho, Kita-gun, Takamatsu, Kagawa 761-0793, Japan

E-mail: tmasaki@med.kagawa-u.ac.jp

Abbreviations: Gal-9, Galectin-9; CCK-8, cell counting kit-8; cCK18, caspase-cleaved cytokeratin 18; FITC, fluorescein isothiocyanate; PI, propidium iodide; miRNA, microRNA

Key words: galectin-9, liver metastasis, pancreatic cancer, apoptosis, microRNA

\section{Introduction}

Distant metastasis is a major clinical determinant of the survival of individuals with gastrointestinal cancer. Liver metastasis occurs in $70 \%$ of patients with pancreatic cancer and confers a very poor prognosis. Occult liver metastases may already be present at the time of surgery (1) and recur, resulting in early mortality after surgical resection (2).

Gal-9, a member of the $\beta$-galactoside-binding animal lectin family, is a promising agent for the treatment of immunerelated and neoplastic diseases. Gal-9 is a tandem-repeat-type galectin family member consisting of two carbohydrate recognition domains connected by a linker peptide (3) and was first described as an eosinophil chemoattractant (4). This protein has been reported to contribute to various biological processes, including cell aggregation, adhesion, chemoattraction, and apoptosis (5). Furthermore, Gal-9 has been tested as a potential therapeutic agent for various autoimmune diseases and allergic diseases (6,7). The functions of Gal-9 have been reported to include the induction of apoptosis in T-cells, particularly CD4 ${ }^{+}$Th1 and Th17 cells, and the stimulation of regulatory T-cell activity (8-10). Recently, it has been reported that Gal-9 suppresses tumor growth in various types of human cancer $(10,11)$, such as melanoma (12) and chronic myelogenous leukemia (13). Regarding the mechanism underlying the Gal-9-induced inhibition of cell growth in various cancers, Gal-9 has been shown to induce cancer cell death via an apoptotic signaling pathway $(12,13)$. This apoptotic signaling in multiple myeloma is caspase-dependent and is induced by activation of the JNK and p38 MAP kinases (14). Alternatively, Gal-9 induces apoptosis in chronic myelogenous leukemia by increasing Noxa expression (13). Recently, it was revealed that Gal-9 shows potent cytotoxic activity toward KRAS mutant colon cancer via the induction of frustrated autophagy (15). Furthermore, loss of Gal-9 expression is associated with metastatic progression in various epithelial cancers, including breast cancer and hepatocellular carcinoma $(16,17)$.

We have previously shown that Gal-9 suppresses cell proliferation and tumor growth in various types of gastrointestinal tumors, such as hepatocellular carcinoma (18), 
cholangiocarcinoma (19), gallbladder carcinoma (20), and gastric cancer (21) by inducing apoptosis, and we have identified several microRNAs (miRNAs) that are associated with the antitumor effect of Gal-9.

miRNAs, which are small, endogenous, non-coding RNAs of 21-30 nucleotides in length, modulate the expression of various target genes at the post-transcriptional and translational levels $(22,23)$. A total of 1,881 human miRNAs are registered at miRbase as of release 21 (http://microrna. sanger.ac.uk/). However, little is known about the association of certain miRNAs with the antitumor effects of Gal-9 on liver metastasis.

Therefore, the purpose of the present study was to determine whether Gal-9 suppresses the tumor growth of liver metastases and to identify the mechanism of the antitumor effect.

\section{Materials and methods}

Chemicals. A mutant form of Gal-9 lacking the entire linker region that is stable against proteolysis was recombinantly produced as previously described (24).

Cell lines and culture. Three human liver metastasis cell lines were derived from pancreatic cancer (KMP2, KMP7 and KMP8) and obtained from the Japanese Collection of Research Bioresources (Osaka, Japan). The cells were cultured in RPMI-1640 (Gibco, Tokyo, Japan) and Ham's F12 medium (Sigma-Aldrich, St. Louis, MO, USA) (1 to $1 \mathrm{mix}$ ) with $5 \%$ heat-inactivated fetal bovine serum (Wako Pure Chemical Industries, Osaka, Japan) and $100 \mathrm{mg} / \mathrm{l}$ penicillin-streptomycin (Invitrogen, Tokyo, Japan), and the cells were incubated in a humidified atmosphere containing $5 \% \mathrm{CO}_{2}$ at $37^{\circ} \mathrm{C}$.

Cell proliferation assay. Cell proliferation assays were conducted using a cell counting kit-8 (CCK-8) kit (Dojindo Laboratories, Kumamoto, Japan) according to the manufacturer's instructions. Cells $\left(5.0 \times 10^{3}\right)$ from each cell line were seeded into the wells of a 96-well plate and cultured in $100 \mu \mathrm{l}$ of the corresponding medium. After $24 \mathrm{~h}$, the seeded cells were treated with $0,0.1$ or $0.3 \mu \mathrm{M}$ Gal-9 diluted in the culture medium. At the indicated time-points, the medium was changed to $100 \mu \mathrm{l}$ of medium containing the CCK-8 reagent, and the cells were incubated for $3 \mathrm{~h}$. The absorbance at a wavelength of $450 \mathrm{~nm}$ was measured in each well using an automated microplate reader.

Enzyme-linked immunosorbent assay (ELISA) for quantification of apoptosis. KMP8 was chosen as a model cell line because it was most sensitive to Gal-9 in vitro. Caspase-cleaved cytokeratin 18 (cCK18) was evaluated using the M30 Apoptosense ELISA kit obtained from PEVIVA AB (Bromma, Sweden) (25). KMP8 cells $\left(5 \times 10^{3}\right)$ were seeded in a 96-well plate and cultured for 6,24 , or $48 \mathrm{~h}$ following the addition of $0.3 \mu \mathrm{M} \mathrm{Gal}-9$. The cells were then lysed in polyoxyethylene octylphenyl ether (NP-40) (Wako Pure Chemical Industries). The subsequent ELISAs were performed according to the manufacturer's instructions. The absorbance at a wavelength of $450 \mathrm{~nm}$ was measured in each well using an automated microplate reader. The abundance of the antigen in the control and unknown samples was calculated via interpolation from a standard curve.
Analysis of early apoptosis. Analysis of early apoptosis was performed using an Annexin V-FITC Early Apoptosis Detection kit (\#6592; Cell Signaling Technology, Boston, MA, USA), which can distinguish early apoptotic cells within a cell population. KMP8 cells $\left(1.0 \times 10^{6}\right.$ cells in a 60 -mm-diameter dish) were treated with or without $0.3 \mu \mathrm{M} \mathrm{Gal}-9$ for $6 \mathrm{~h}$. Because of the high sensitivity of the cells to Gal-9, they were not suitable for analysis at the 12- and 24-h time-points. Apoptotic and necrotic cell death was analyzed through double staining with FITC-conjugated Annexin V and propidium iodide (PI); this staining method is based on the binding of Annexin V to apoptotic cells with exposed phosphatidyl-serines and the PI labeling of late apoptotic/necrotic cells with membrane damage. Staining was performed according to the manufacturer's instructions. Flow cytometry was conducted using a Cytomics FC 500 flow cytometer (Beckman Coulter, Indianapolis, IN, USA). Cell percentages were analyzed using Kaluza software (Beckman Coulter). The experiment was repeated five times, and a test for significant difference was carried out.

Analysis of apoptosis-related protein profiles using an antibody array. Cells were seeded in 100-mm culture dishes and were then treated with $0.3 \mu \mathrm{M}$ Gal-9 for $6 \mathrm{~h}$, followed by lysis in PRO-PREP (iNtRON Biotechnology, Sungnam, Korea). A human apoptosis antibody array kit (R\&D Systems, Minneapolis, MN, USA) was subsequently used to measure apoptosis-related proteins according to the manufacturer's instructions. Briefly, proteins were captured by antibodies spotted on a nitrocellulose membrane. Next, the levels of apoptosis-related proteins were assessed using an HRP-conjugated antibody, followed by detection via chemiluminescence. Finally, each array membrane was exposed to X-ray film using a chemiluminescence detection system (Perkin-Elmer Co. Waltham, MA, USA).

Gel electrophoresis and western blot analysis. KMP8 cells (1.0x $\left.10^{6} / \mathrm{dish}\right)$ were seeded in $100-\mathrm{mm}$ culture dishes and cultured for 6 or $12 \mathrm{~h}$, after which 0 or $0.3 \mu \mathrm{M}$ Gal-9 was added. The cells were subsequently lysed using a protease inhibitor cocktail (PRO-PREP complete protease inhibitor mixture; iNtRON Biotechnology). Furthermore, to investigate cytoplasmic proteins, a Cell Fractionation kit (Cell Signaling Technology) was used according to the manufacturer's instructions. Briefly, the cells (cultured for $6 \mathrm{~h}$ after the addition of 0 or $0.3 \mu \mathrm{M} \mathrm{Gal}-9)$ were separated into three distinct fractions: cytoplasmic, membrane/organelle, and nuclear/cytoskeletal, using the appropriate isolation buffer for each process. Next, the samples were subjected to sodium dodecyl sulfate-polyacrylamide gel electrophoresis (SDS-PAGE) in 12\% agarose gels, and the proteins were transferred to nitrocellulose membranes. After blocking, the membranes were first incubated with primary antibodies, followed by secondary antibodies. The immunoreactive proteins were visualized on X-ray film using an enhanced chemiluminescence detection system (Perkin-Elmer Co.).

Primary antibodies against caspase-3 (8G10) (\#9665), cleaved caspase-3 (D175) (\#1661), caspase-7 (D2Q3L) (\#12827), caspase-9 (C9) (\#9508), cleaved caspase-9 (Asp330) (\#7237), PARP (\#9542), cleaved-PARP (D64E10) (\#5625), cytochrome $c$ 

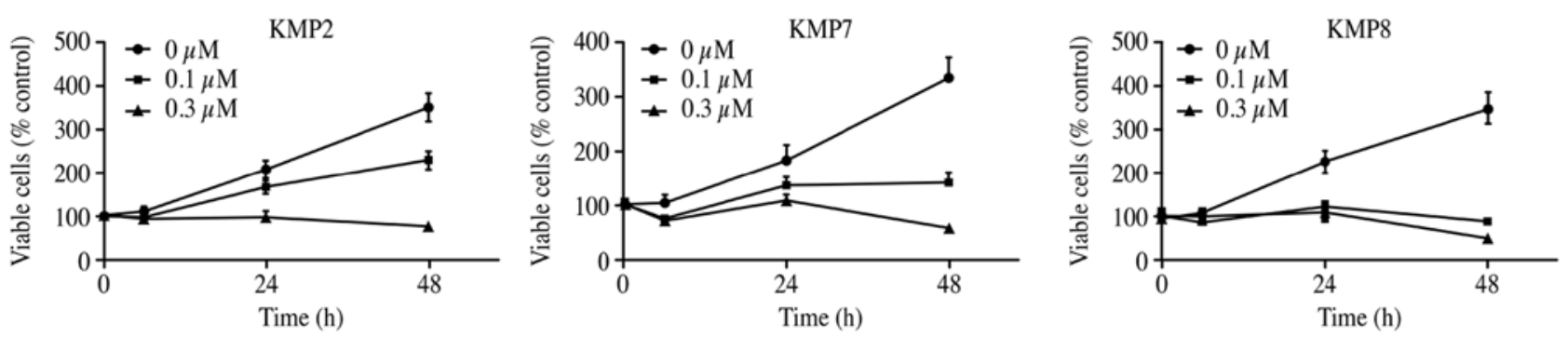

Figure 1. Galectin-9 (Gal-9) suppresses the proliferation of liver metastasis cell lines. KMP2, KMP7 and KMP8 cells were seeded at 5,000 cells/well in 96-well plates. After $24 \mathrm{~h}$, Gal-9 $(0,0.1$ or $0.3 \mu \mathrm{M})$ was added to the culture medium. At $24 \mathrm{~h}$ after the addition of the agent, the cell counting kit- 8 assay was conducted as described in the Materials and methods. The results are expressed as the percentages of viable cells relative to the control treatment $(0 \mu \mathrm{M})$, and the error bars represent SD. In each cell line, cell viability at 24 and $48 \mathrm{~h}$ after Gal-9 treatment was significantly different compared with that in the control.

(D18C7) (\#11940), Smac/Diablo (\#2954), HtrA2/Omi (D20A5) (\#9745), and GAPDH (D16H11) XP (\#5174) were purchased from Cell Signaling Technology. Additionally, an anti- $\beta$-actin monoclonal antibody (A5441; Sigma-Aldrich) and antibodies against cyclin D1 (RB-9041; Thermo Fisher Scientific, Waltham, MA, USA), cyclin E (HE12) (MA5-14336; Thermo Fisher Scientific), Cdk6 (sc-177; Santa Cruz Biotechnology, Santa Cruz, CA), Cdk4 (sc-749; Santa Cruz Biotechnology), and Cdk2 (sc-163; Santa Cruz Biotechnology) were used. The secondary antibodies included horseradish peroxidase (HRP)-linked antimouse and anti-rabbit IgG (GE Healthcare, UK).

Analysis of miRNA arrays. Five culture dishes of KMP8 cells were treated with $0.3 \mu \mathrm{M}$ Gal-9 for $6 \mathrm{~h}$; another five dishes of KMP8 cells were used as a control without Gal-9 treatment. Those cells were stored in the RNAprotect reagent (Qiagen, Venlo, The Netherlands). All samples were processed for total RNA extraction using miRNeasy Mini kit (Qiagen) according to the manufacturer's instructions. After the assessment of RNA quantity and quality using the RNA 6000 Nano kit (Agilent Technologies, Santa Clara, CA, USA), the samples were labeled using the miRCURY Hy3 Power Labeling kit (Exiqon, Vedbaek, Denmark) and then hybridized to a human miRNA Oligo chip (v.21; Toray Industries, Tokyo, Japan). Scanning was conducted using a 3D-Gene Scanner 3000 (Toray Industries). 3D-Gene Extraction version 1.2 software (Toray Industries) was employed to calculate the raw intensity of the images. To determine the difference in miRNA expression between the Gal-9-treated and control samples, the raw data were analyzed using GeneSpring GX 10.0 software (Agilent Technologies). For the raw data that were above the background level, quantile normalization was performed. Differentially expressed miRNAs were determined with the Mann-Whitney U test. Unsupervised hierarchical clustering was performed on the normalized data, which consisted of ten observations of the five treated and five control experiments, using the farthest neighbor method employing the absolute uncentered Pearson's correlation coefficient as a metric. A heat map was produced using the relative expression intensity for each miRNA, in which the base- 2 logarithm of the intensity was median centered for each row.

Statistical analysis. All of the analyses were conducted using GraphPad Prism software version 6.0 (GraphPad Software, San Diego, CA, USA). Unpaired t-tests were conducted for comparisons between groups. A P-value of 0.05 was considered to indicate a significant difference between the groups.

\section{Results}

Gal-9 suppresses the proliferation of human liver metastasis cells (KMP2, KMP7 and KMP8 cells). To evaluate the effect of Gal-9 on the growth activity of human liver metastasis cells in vitro, we examined the effect of Gal-9 on cell proliferation in three liver metastasis cell lines (KMP2, KMP7 and KMP8 cells) cultured for $48 \mathrm{~h}$ with $0,0.1$ or $0.3 \mu \mathrm{M}$ Gal-9 in the corresponding medium. We found that Gal-9 suppressed cell proliferation in the three liver metastasis cell lines in a doseand time-dependent manner (Fig. 1).

Gal-9 induces apoptosis of liver metastasis cells. To determine whether Gal-9 induced apoptosis, KMP8 cells were treated with or without $0.3 \mu \mathrm{M} \mathrm{Gal}-9$, and the levels of cCK18 following treatment were determined using the M30 ELISA kit. We found that Gal-9 significantly increased the levels of cCK18 in KMP8 cells in a time-dependent manner (Fig. 2A). The experiments were repeated three times, and the same results were obtained. Additionally, Gal-9 induced early apoptosis of KMP8 cells, as determined by Annexin V-FITC/PI staining and flow cytometry. The different quadrants in Fig. 2B represent living cells (lower left quadrant), early apoptotic cells (lower right quadrant), and late apoptotic cells (upper right quadrant). As demonstrated by the increased numbers of earlyphase apoptotic cells, the antitumor effects of Gal-9 begin at an early stage, with a significant difference observed (Fig. 2C).

Effects of Gal-9 on the levels of apoptosis-associated proteins. Next, we used an apoptosis array system to identify which apoptosis-associated proteins are involved in the antitumor effects of Gal-9. Using an antibody array enabled screening of the expression of 35 apoptosis-associated proteins in KMP8 cells in the presence or absence of Gal-9, but there was no change in this array system (Fig. 3A and B).

Furthermore, we investigated apoptosis-associated proteins including caspase-3,-7,-9, PARP, cleaved caspase- 3 and cleaved PARP; Gal-9 activated caspase-7 slightly at $6 \mathrm{~h}$, and cleaved caspase-3 and cleaved PARP were activated at $12 \mathrm{~h}$ after Gal-9 treatment (Fig. 3C). Next, we examined the intracellular distribution of the apoptosis-related molecules. In cytoplasmic fractions, the levels of cytochrome $c$, Smac/Diablo and 
A
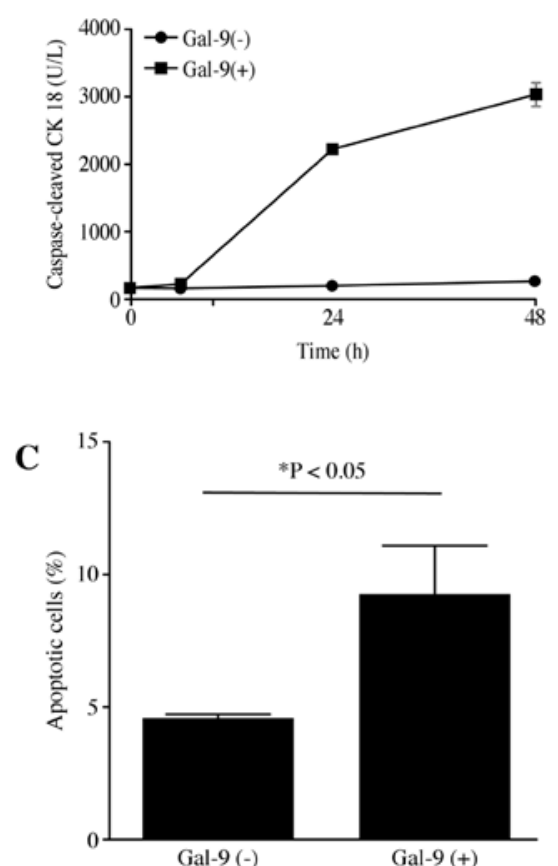

B
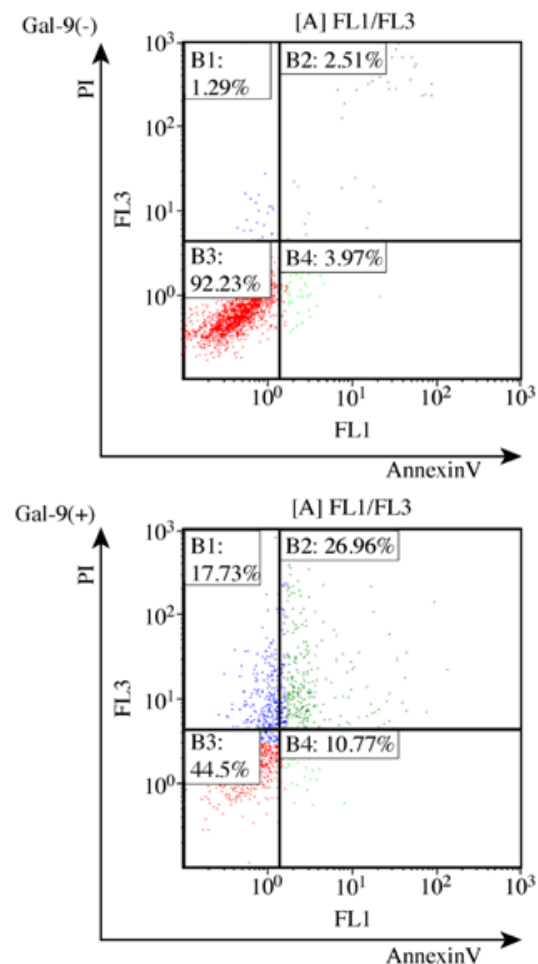

Figure 2. Gal-9 induces apoptosis of KMP8 cells. (A) The levels of caspase-cleaved keratin 18 (cCK18), which is specifically produced during apoptosis, were determined via ELISA. Cells were incubated in 0 or $0.3 \mu \mathrm{M}$ Gal-9. In KMP8 cells, the cCK18 levels at 24 and $48 \mathrm{~h}$ were significantly different between the Gal-9-treated group and the control $(0 \mu \mathrm{M} \mathrm{Gal-9)}$ group. (B and C) Apoptosis in KMP8 cells treated with or without $0.3 \mu \mathrm{M}$ Gal-9 for $6 \mathrm{~h}$ [x-axis, Annexin V-FITC; y-axis, propidium iodide (PI)]. Analysis of apoptosis via flow cytometry showed that Gal-9 induced cell apoptosis in the early stage.

A

\begin{tabular}{|c|c|c|c|c|c|c|c|c|c|c|c|}
\hline $\begin{array}{c}\text { Reference } \\
\text { Spots }\end{array}$ & & & & & & & & & & & $\begin{array}{c}\text { Reference } \\
\text { Spots }\end{array}$ \\
\hline Bad & Bax & $\mathrm{Bcl}-2$ & Bcl-x & $\begin{array}{c}\text { Pro- } \\
\text { Caspase-3 }\end{array}$ & $\begin{array}{c}\text { Cleaved } \\
\text { Caspase-3 } \\
\end{array}$ & Catalase & cIAP-1 & clAP-2 & Claspin & Clusterin & \begin{tabular}{|c} 
Cyto- \\
chrome C
\end{tabular} \\
\hline $\begin{array}{l}\text { TRAIL } \\
\text { R1/DR4 }\end{array}$ & $\begin{array}{l}\text { TRAIL } \\
\text { R2/DR5 }\end{array}$ & FADD & $\begin{array}{c}\text { Fas/ } \\
\text { TNFRSF6 } \\
\text { /CD95 } \\
\end{array}$ & HIF- $1 \alpha$ & $\begin{array}{c}\text { HO-1/ } \\
\text { HMOX1/ } \\
\text { HSP32 }\end{array}$ & $\begin{array}{c}\text { HO-2/ } \\
\text { HMOX2 }\end{array}$ & HSP 27 & HSP 60 & HSP 70 & $\begin{array}{c}\text { HTRA/ } \\
\text { Omi }\end{array}$ & Livin \\
\hline PON2 & $\begin{array}{l}\text { p21/CIPI/ } \\
\text { CDKNIA }\end{array}$ & P27/Kipl & $\begin{array}{l}\text { Phospho- } \\
\text { p53(S15) }\end{array}$ & $\begin{array}{l}\text { Phospho- } \\
\text { p53(S46) }\end{array}$ & $\begin{array}{l}\text { Phospho- } \\
\text { p53(S392) }\end{array}$ & $\begin{array}{l}\text { Phospho- } \\
\text { Rad17 } \\
\text { (S635) }\end{array}$ & $\begin{array}{l}\text { SMAC/ } \\
\text { Diablo }\end{array}$ & Survivin & $\begin{array}{c}\text { TNF RI/ } \\
\text { TNF } \\
\text { RSFIA }\end{array}$ & XIAP & $\begin{array}{c}\text { PBS } \\
\text { (Negative } \\
\text { control) }\end{array}$ \\
\hline $\begin{array}{c}\text { Reference } \\
\text { Spots }\end{array}$ & & & & & & & & & & & $\begin{array}{c}\text { Reference } \\
\text { Spots }\end{array}$ \\
\hline
\end{tabular}

B

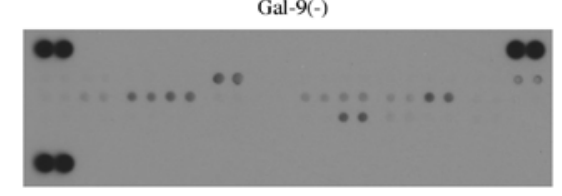

C

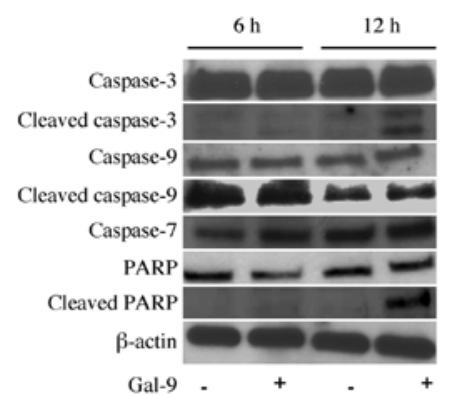

Gal-9(+)

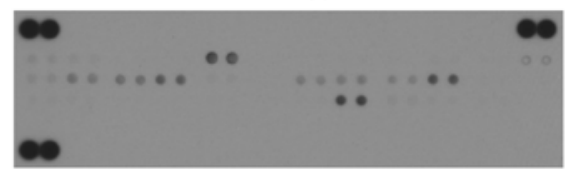

D

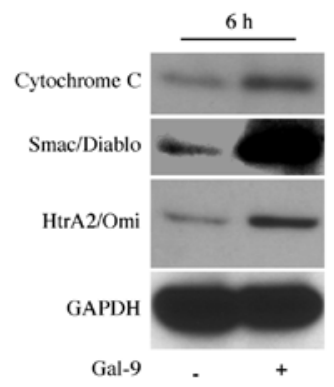

Figure 3. Effects of Gal-9 on the levels of apoptosis-related proteins in KMP8 cells. (A) Template showing the location of representative apoptosis-related proteins in the human apoptosis antibody array. (B) Representative expression levels of various apoptosis-related proteins in KMP8 cells treated with or without $0.3 \mu \mathrm{M}$ Gal-9 for $6 \mathrm{~h}$. The array showed no change following treatment with Gal-9. (C) Western blotting revealed the effects of Gal-9 on caspase-7 at $6 \mathrm{~h}$ after Gal-9 treatment. (D) In cytoplasmic fractions, the levels of cytochrome $c$, Smac/Diablo and HtrA2 were increased in the Gal-9-treated group. 


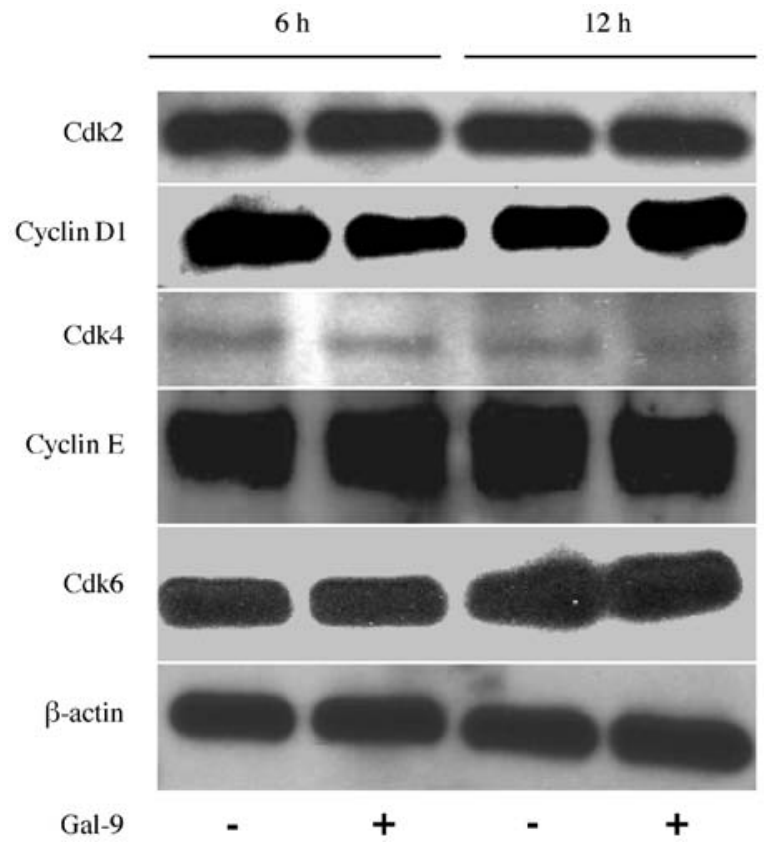

Figure 4. Western blotting of cell cycle-related proteins in KMP8 cells. The expression levels of cell cycle-related proteins (cyclin D1, Cdk4, Cdk6, cyclin E and Cdk2) in KMP8 cells did not differ between the $0.3 \mu \mathrm{M}$ Gal-9-treated group and the control based on western blotting.

HtrA2 were increased in the Gal-9-treated group (Fig. 3D). These results demonstrated potential apoptotic mechanisms, including involvement of the mitochondrial apoptotic pathway. Thus, Gal-9 suppressed the proliferation of KMP8 cells by inducing apoptosis via the intrinsic apoptosis pathway.

No specific effects of Gal-9 were observed on cell cycle regulatory proteins in liver metastasis cells. As Gal-9 suppressed cell proliferation very significantly, we considered whether there was a route other than apoptosis induction and investigated the effects of Gal-9 on the cell cycle. The effects of Gal-9 on the expression of various cell cycle-related proteins in KMP8 cells were evaluated through western blotting. Cells were treated with 0 or $0.3 \mu \mathrm{M}$ Gal-9 for $6-12 \mathrm{~h}$, and we then examined the levels of various cell cycle-related molecules, such as cyclin D1, Cdk4, Cdk6, cyclin E, and Cdk2. However, no significant differences in the expression of these cell cyclerelated proteins were detected (Fig. 4). These results suggested that Gal-9 suppresses the proliferation of KMP8 cells predominantly by inducing apoptosis, and not by promoting cell cycle arrest.

Effects of Gal-9 on miRNA expression in KMP8 cells. To further examine the antitumor effect of Gal-9, we screened the expression levels of miRNAs in KMP8 cells and compared the miRNA profiles obtained with or without Gal-9 treatment. KMP8 cells were treated with 0 or $0.3 \mu \mathrm{M}$ Gal-9 for $6 \mathrm{~h}$. Unsupervised hierarchical clustering analysis showed that the treated group clustered separately from the control group (Fig. 5). We identified 42 miRNAs that were differentially expressed between the two groups of KMP8 cells among the 2,555 miRNAs (21 upregulated miRNAs and 21 downregulated miRNAs) (Table I).
Table 1. Statistical results for miRNAs in KMP8 cells treated with Gal-9 compared with untreated KMP8 cells.

\begin{tabular}{lccc}
\hline $\begin{array}{l}\text { Upregulated } \\
\text { microRNAs }\end{array}$ & $\begin{array}{c}\text { Fold-change } \\
\text { (Gal-9 treated/ } \\
\text { non-treated) }\end{array}$ & P-value & $\begin{array}{c}\text { Chromosomal } \\
\text { localization }\end{array}$ \\
\hline hsa-miR-6124 & 1.70 & 0.0079 & 11 \\
hsa-miR-4488 & 1.30 & 0.0079 & 11 \\
hsa-miR-6842-5p & 1.25 & 0.0317 & 8 \\
hsa-miR-6131 & 1.25 & 0.0119 & 5 \\
hsa-miR-6826-3p & 1.23 & 0.0159 & 3 \\
hsa-miR-4451 & 1.22 & 0.0465 & 4 \\
hsa-miR-1587 & 1.21 & 0.0278 & $\mathrm{Xp} 11.4$ \\
hsa-miR-4739 & 1.21 & 0.0117 & 17 \\
hsa-miR-6763-5p & 1.20 & 0.0208 & 12 \\
hsa-miR-6778-5p & 1.20 & 0.0079 & 17 \\
hsa-miR-4657 & 1.19 & 0.0465 & 7 \\
hsa-miR-6089 & 1.18 & 0.0259 & $\mathrm{Xp} 22.3$ \\
hsa-miR-4655-5p & 1.17 & 0.0079 & 7 \\
hsa-miR-328-5p & 1.16 & 0.0119 & $16 \mathrm{q} 22.1$ \\
hsa-miR-4667-5p & 1.12 & 0.0345 & 9 \\
hsa-miR-4763-3p & 1.10 & 0.0361 & 22 \\
hsa-miR-187-5p & 1.08 & 0.0269 & $18 \mathrm{q} 12.2$ \\
hsa-miR-27a-3p & 1.08 & 0.0238 & $19 \mathrm{p} 13.13$ \\
hsa-miR-4286 & 1.07 & 0.0413 & 8 \\
hsa-miR-4651 & 1.05 & 0.0196 & 7 \\
hsa-miR-4484 & 1.05 & 0.0445 & 10 \\
\hline & & & \\
\hline
\end{tabular}

\begin{tabular}{lccc}
\hline $\begin{array}{l}\text { Downregulated } \\
\text { microRNAs }\end{array}$ & $\begin{array}{c}\text { Fold-change } \\
\text { (Gal-9 treated/ } \\
\text { non-treated) }\end{array}$ & P-value & $\begin{array}{c}\text { Chromosomal } \\
\text { localization }\end{array}$ \\
& & \\
\hline
\end{tabular}

\begin{tabular}{llcc}
\hline hsa-miR-3154 & 0.59 & 0.0119 & 9 \\
hsa-miR-93-3p & 0.67 & 0.0079 & $7 \mathrm{q} 22.1$ \\
hsa-miR-503-5p & 0.67 & 0.0317 & $\mathrm{Xq} 26.3$ \\
hsa-miR-4442 & 0.72 & 0.0079 & 3 \\
hsa-miR-4459 & 0.77 & 0.0465 & 5 \\
hsa-miR-934 & 0.81 & 0.0079 & $\mathrm{Xq} 26.3$ \\
hsa-miR-6850-5p & 0.84 & 0.0317 & 8 \\
hsa-miR-146a-5p & 0.85 & 0.0465 & $5 \mathrm{q} 33.3$ \\
hsa-miR-3607-3p & 0.87 & 0.0356 & \\
hsa-miR-3687 & 0.87 & 0.0317 & 21 \\
hsa-miR-421 & 0.87 & 0.0317 & $\mathrm{Xq} 13.2$ \\
hsa-miR-196b-5p & 0.88 & 0.0465 & $7 \mathrm{p} 15.2$ \\
hsa-miR-6516-5p & 0.89 & 0.0119 & 17 \\
hsa-miR-181d-5p & 0.89 & 0.0459 & $19 \mathrm{p} 13.13$ \\
hsa-miR-3178 & 0.90 & 0.0426 & 16 \\
hsa-miR-1909-3p & 0.90 & 0.0317 & $19 \mathrm{p} 13.3$ \\
hsa-miR-4289 & 0.90 & 0.0273 & 9 \\
hsa-miR-663a & 0.91 & 0.0465 & $20 \mathrm{p} 11.1$ \\
hsa-miR-196a-5p & 0.93 & 0.0189 & \\
hsa-miR-221-3p & 0.94 & 0.0118 & $\mathrm{Xp} 11.3$ \\
hsa-miR-151a-3p & 0.94 & 0.0196 & $8 \mathrm{q} 24.3$ \\
\hline
\end{tabular}




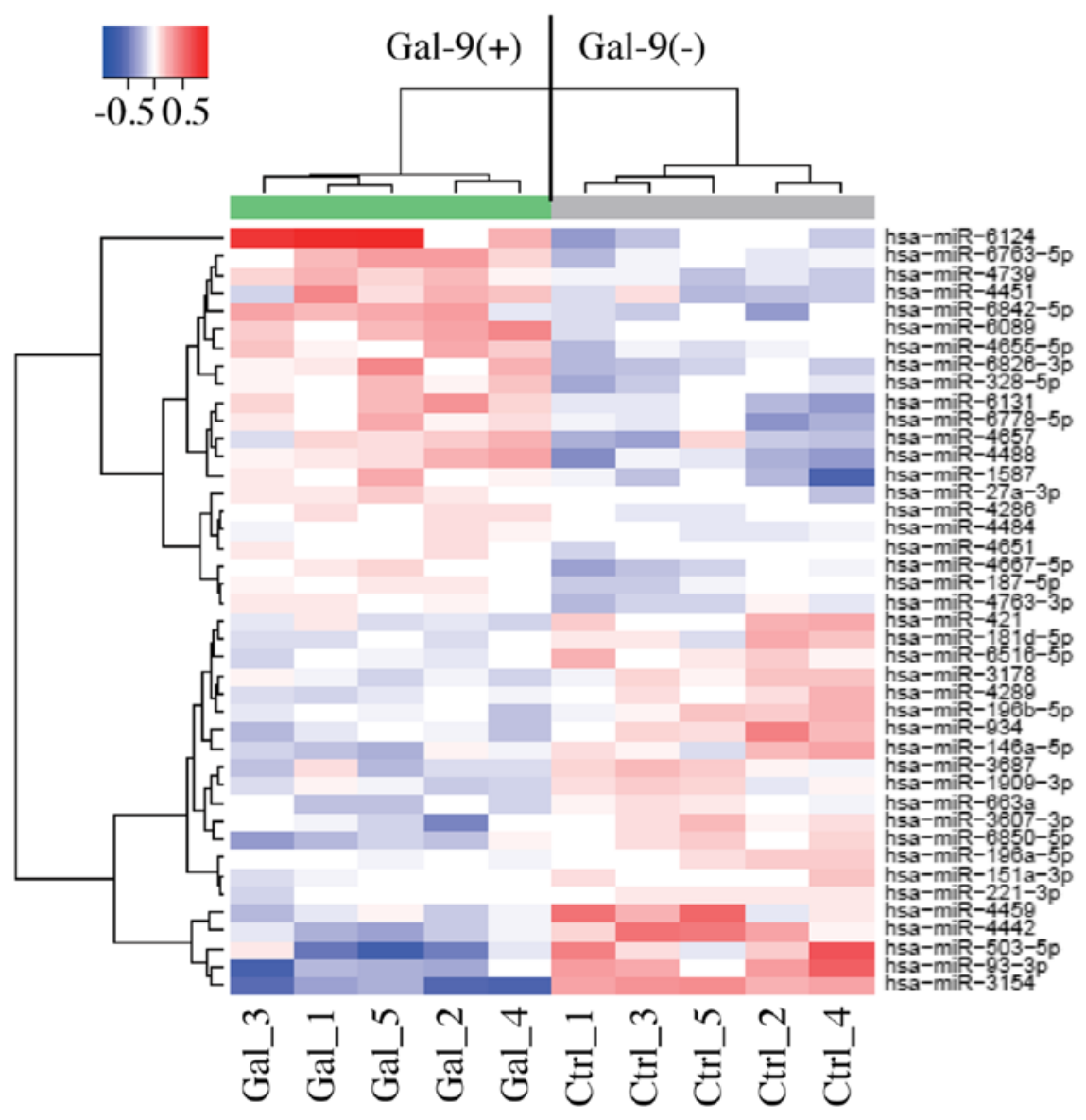

Figure 5. Hierarchical clustering analysis of KMP8 cells with or without Gal-9 treatment. KMP8 cells were clustered according to the expression profiles of 42 differentially expressed miRNAs between tumor cells exposed to Gal-9 and those that were not treated with Gal-9. The analyzed samples are shown in the columns, and the miRNAs are presented in separate rows. The color scale at the top indicates the relative expression levels of the miRNAs; red indicates a high expression level, and blue indicates a low expression level.

\section{Discussion}

The present study revealed that Gal-9 led to dose- and time-dependent inhibition of cell proliferation in liver metastasis cell lines. In this study, Gal-9 increased the levels of cCK18 in a time-dependent manner. A neo-epitope in cytokeratin 18 becomes available upon an early caspase cleavage event during apoptosis, and the monoclonal antibody M30, which is specific for this site, can be utilized to specifically detect apoptotic cells, and not necrotic cells (26). This assay measures the accumulation of cCK18 in cells; thus, we investigated the initiation of apoptosis using Annexin V-FITC/PI staining and flow cytometry. Annexin V-FITC is an early apoptosis marker, and PI indicates necrotic cells. Staining of cells with both PI and Annexin V-FITC demonstrates later-stage apoptosis and early necrosis. Gal-9 induced early apoptosis of KMP8 cells, as determined by Annexin V-FITC/PI staining and flow cytometry. Next, we investigated the changes in apoptotic molecules with or without Gal-9. Cleaved caspase-3, cleaved PARP, and caspase-7, which are apoptosis-related proteins (27), were activated by Gal-9. Subsequently, we investigated the intracellular distribution of apoptosis-related molecules and Gal-9 activated cytochrome c, Smac/Diablo and $\mathrm{HtrA} 2$ in cytoplasmic fractions. Cytochrome $c$ released from damaged mitochondria can initiate the activation cascade of caspases once it is released into the cytosol (28). This is a very early event in the intrinsic apoptosis pathway and contributes to caspase-9 activation. Furthermore, mitochondria release multiple pro-apoptotic molecules, such as Smac/ Diablo and HtrA2, in addition to cytochrome $c$. Smac/Diablo and HtrA2/Omi, which are mitochondrial proteins that are released together with cytochrome $c$, suppress the inhibitor of apoptosis protein (IAP) and increase caspase activity (29-31). In contrast, Gal-9 treatment for 6 or $12 \mathrm{~h}$ did not affect the G0-G1 transition or the expression levels of cell cycle-related proteins. These data suggest that Gal-9 suppresses cell proliferation in liver metastasis cell lines by inducing apoptosis, and not by promoting cell cycle arrest.

The miRNAs associated with the antitumor effects of Gal-9 were analyzed using miRNA expression arrays. It has become apparent that miRNA expression is associated with various cancers. Our previous studies revealed that miRNAs lead to apoptosis as a consequence of the antitumor effect of Gal-9 in various gastrointestinal cancers (18-21). Hierarchical cluster analyses were performed to clarify the alteration of the expression of miRNAs due to Gal-9 treatment. We identified 42 differentially expressed miRNAs (21 upregulated and 21 downregulated) in KMP8 cells that were either subjected to Gal-9 treatment or not. Among the miRNAs downregulated by Gal-9, miR-196a overexpression has been observed in several 
types of cancers, and high expression of miR-196a has been associated with a poor prognosis in pancreatic cancer (32). miR-221 targets p27 and DNA damage-inducible transcript 4 (DDIT4), and overexpression of miR-221 stimulates liver tumorigenesis (33). In addition, miR-93 inhibits the expression of Programmed cell death 4 (PDCD4), a tumor suppressor gene, and consequently inhibits apoptosis in gastric cancer cells (34). These findings suggest that Gal-9 induces apoptosis by altering the expression of several miRNAs.

In conclusion, Gal-9 suppresses the cell proliferation and tumor growth of human liver metastases in vitro. The antitumor effect of Gal-9 appears to depend on several pathways, such as the induction of apoptosis in cancer cells via multiple pro-apoptotic molecules, including Smac/Diablo and HtrA2, and cytochrome $c$ release from mitochondria. However, Gal-9 was found to have little or no effect on the cell cycle in this study and in our previous studies (18-21). The statistical superiority or non-inferiority of certain chemotherapy regimens has been demonstrated by phase III trials of unresectable pancreatic cancer (including distant metastasis cases), including gemcitabine (35), S-1 (36), oxaliplatin plus irinotecan, leucovorin, fluorouracil (FOLFIRINOX) (37), and nab-paclitaxel plus gemcitabine (38). Paclitaxel promotes the accelerated assembly of excessively stable microtubules and induces apoptosis, which are the main mechanisms of its antitumor effect (39). Furthermore, many antitumor drugs, such as gemcitabine and fluorouracil, have an effect on the cell cycle (40). These results suggest that a combination of the apoptosis inducer Gal-9 with other antitumor drugs that induce cell cycle arrest would be more effective for cancer therapy.

Thus, Gal-9 may represent a novel therapeutic agent as an adjunct to conventional chemotherapy for the treatment of liver metastasis.

\section{Acknowledgements}

We thank Ms. Kayo Hirose, Ms. Keiko Fujikawa, Ms. Megumi Okamura, Ms. Fuyuko Kokado and Ms. Miwako Watanabe for providing technical assistance.

\section{References}

1. Qian Y, Sang Y, Wang FX, Hong B, Wang Q, Zhou X, Weng T, Wu Z, Zheng M, Zhang H, et al: Prognostic significance of B7-H4 expression in matched primary pancreatic cancer and liver metastases. Oncotarget 7: 72242-72249, 2016.

2. Takamori H, Hiraoka T, Kanemitsu K, Tsuji T, Hamada C and Baba H: Identification of prognostic factors associated with early mortality after surgical resection for pancreatic cancer - underanalysis of cumulative survival curve. World J Surg 30: 213-218, 2006.

3. Miyanishi N, Nishi N, Abe H, Kashio Y, Shinonaga R, Nakakita S, Sumiyoshi W, Yamauchi A, Nakamura T, Hirashima M, et al: Carbohydrate-recognition domains of galectin-9 are involved in intermolecular interaction with galectin-9 itself and other members of the galectin family. Glycobiology 17: 423-432, 2007.

4. Matsumoto R, Matsumoto H, Seki M, Hata M, Asano Y, Kanegasaki S, Stevens RL and Hirashima M: Human ecalectin, a variant of human galectin-9, is a novel eosinophil chemoattractant produced by T lymphocytes. J Biol Chem 273: 16976-16984, 1998.

5. Hirashima M, Kashio Y, Nishi N, Yamauchi A, Imaizumi TA, Kageshita T, Saita N and Nakamura T: Galectin-9 in physiological and pathological conditions. Glycoconj J 19: 593-600, 2004
6. Seki M, Oomizu S, Sakata KM, Sakata A, Arikawa T, Watanabe K, Ito K, Takeshita K, Niki T, Saita N, et al: Galectin-9 suppresses the generation of Th17, promotes the induction of regulatory $\mathrm{T}$ cells, and regulates experimental autoimmune arthritis. Clin Immunol 127: 78-88, 2008.

7. Niki T, Tsutsui S, Hirose S, Aradono S, Sugimoto $Y$, Takeshita K, Nishi N and Hirashima M: Galectin-9 is a high affinity IgE-binding lectin with anti-allergic effect by blocking IgE-antigen complex formation. J Biol Chem 284: 32344-32352, 2009.

8. Zhu C, Anderson AC, Schubart A, Xiong H, Imitola J, Khoury SJ, Zheng XX, Strom TB and Kuchroo VK: The Tim-3 ligand galectin-9 negatively regulates $\mathrm{T}$ helper type 1 immunity. Nat Immunol 6: 1245-1252, 2005

9. Oomizu S, Arikawa T, Niki T, Kadowaki T, Ueno M, Nishi N, Yamauchi A and Hirashima M: Galectin-9 suppresses Th17 cell development in an IL-2-dependent but Tim-3-independent manner. Clin Immunol 143: 51-58, 2012.

10. Wiersma VR, de Bruyn M, Helfrich W and Bremer E: Therapeutic potential of Galectin-9 in human disease. Med Res Rev 33 (Suppl 1): E102-E126, 2013.

11. Fujihara S, Mori H, Kobara H, Rafiq K, Niki T, Hirashima M and Masaki T: Galectin-9 in cancer therapy. Recent Pat Endocr Metab Immune Drug Discov 7: 130-137, 2013.

12. Kageshita T, Kashio Y, Yamauchi A, Seki M, Abedin MJ, Nishi N, Shoji H, Nakamura T, Ono T and Hirashima M: Possible role of galectin-9 in cell aggregation and apoptosis of human melanoma cell lines and its clinical significance. Int J Cancer 99: 809-816, 2002.

13. Kuroda J, Yamamoto M, Nagoshi H, Kobayashi T, Sasaki N, Shimura Y, Horiike S, Kimura S, Yamauchi A, Hirashima M, et al: Targeting activating transcription factor 3 by Galectin-9 induces apoptosis and overcomes various types of treatment resistance in chronic myelogenous leukemia. Mol Cancer Res 8: 994-1001, 2010.

14. Kobayashi T, Kuroda J, Ashihara E, Oomizu S, Terui Y, Taniyama A, Adachi S, Takagi T, Yamamoto M, Sasaki N, et al: Galectin-9 exhibits anti-myeloma activity through JNK and p38 MAP kinase pathways. Leukemia 24: 843-850, 2010.

15. Wiersma VR, de Bruyn M, Wei Y, van Ginkel RJ, Hirashima M, Niki T, Nishi N, Zhou J, Pouwels SD, Samplonius DF, et al: The epithelial polarity regulator LGALS9/galectin-9 induces fatal frustrated autophagy in KRAS mutant colon carcinoma that depends on elevated basal autophagic flux. Autophagy 11: 1373-1388, 2015.

16. Irie A, Yamauchi A, Kontani K, Kihara M, Liu D, Shirato Y, Seki M, Nishi N, Nakamura T, Yokomise H, et al: Galectin-9 as a prognostic factor with antimetastatic potential in breast cancer. Clin Cancer Res 11: 2962-2968, 2005.

17. Zhang ZY, Dong JH, Chen YW, Wang XQ, Li CH, Wang J, Wang GQ, Li HL and Wang XD: Galectin-9 acts as a prognostic factor with antimetastatic potential in hepatocellular carcinoma. Asian Pac J Cancer Prev 13: 2503-2509, 2012.

18. Fujita K, Iwama H, Sakamoto T, Okura R, Kobayashi K, Takano J, Katsura A, Tatsuta M, Maeda E, Mimura S, et al: Galectin-9 suppresses the growth of hepatocellular carcinoma via apoptosis in vitro and in vivo. Int J Oncol 46: 2419-2430, 2015.

19. Kobayashi K, Morishita A, Iwama H, Fujita K, Okura R, Fujihara S, Yamashita T, Fujimori T, Kato K, Kamada H, et al: Galectin-9 suppresses cholangiocarcinoma cell proliferation by inducing apoptosis but not cell cycle arrest. Oncol Rep 34: 1761-1770, 2015 .

20. Tadokoro T, Morishita A, Fujihara S, Iwama H, Niki T, Fujita K, Akashi E, Mimura S, Oura K, Sakamoto T, et al: Galectin-9: An anticancer molecule for gallbladder carcinoma. Int J Oncol 48: 1165-1174, 2016.

21. Takano J, Morishita A, Fujihara S, Iwama H, Kokado F, Fujikawa K, Fujita K, Chiyo T, Tadokoro T, Sakamoto T, et al: Galectin-9 suppresses the proliferation of gastric cancer cells in vitro. Oncol Rep 35: 851-860, 2016.

22. Zamore PD and Haley B: Ribo-gnome: The big world of small RNAs. Science 309: 1519-1524, 2005.

23. Morishita A and Masaki T: miRNA in hepatocellular carcinoma. Hepatol Res 45: 128-141, 2015.

24. Nishi N, Itoh A, Fujiyama A, Yoshida N, Araya S, Hirashima M, Shoji H and Nakamura T: Development of highly stable galectins: Truncation of the linker peptide confers protease-resistance on tandem-repeat type galectins. FEBS Lett 579: 2058-2064, 2005. 
25. Schutte B, Henfling M, Kölgen W, Bouman M, Meex S, Leers MP, Nap M, Björklund V, Björklund P, Björklund B, et al: Keratin 8/18 breakdown and reorganization during apoptosis. Exp Cell Res 297: 11-26, 2004.

26. Leers MP, Kölgen W, Björklund V, Bergman T, Tribbick G, Persson B, Björklund P, Ramaekers FC, Björklund B, Nap M, et al: Immunocytochemical detection and mapping of a cytokeratin 18 neo-epitope exposed during early apoptosis. J Pathol 187: 567-572, 1999.

27. Cohen GM: Caspases: The executioners of apoptosis. Biochem J 326: 1-16, 1997.

28. Cai J, Yang J and Jones DP: Mitochondrial control of apoptosis: The role of cytochrome $c$. Biochim Biophys Acta 1366: 139-149, 1998.

29. Du C, Fang M, Li Y, Li L and Wang X: Smac, a mitochondrial protein that promotes cytochrome $c$-dependent caspase activation by eliminating IAP inhibition. Cell 102: 33-42, 2000.

30. Verhagen AM, Ekert PG, Pakusch M, Silke J, Connolly LM, Reid GE, Moritz RL, Simpson RJ and Vaux DL: Identification of DIABLO, a mammalian protein that promotes apoptosis by binding to and antagonizing IAP proteins. Cell 102: 43-53, 2000.

31. Suzuki Y, Imai Y, Nakayama H, Takahashi K, Takio K and Takahashi R: A serine protease, HtrA2, is released from the mitochondria and interacts with XIAP, inducing cell death. Mol Cell 8: 613-621, 2001.

32. Wang J, Chen J, Chang P, LeBlanc A, Li D, Abbruzzesse JL, Frazier ML, Killary AM and Sen S: MicroRNAs in plasma of pancreatic ductal adenocarcinoma patients as novel blood-based biomarkers of disease. Cancer Prev Res (Phila) 2: 807-813, 2009.

33. Pineau P, Volinia S, McJunkin K, Marchio A, Battiston C, Terris B, Mazzaferro V, Lowe SW, Croce CM and Dejean A: miR-221 overexpression contributes to liver tumorigenesis. Proc Natl Acad Sci USA 107: 264-269, 2010
34. Liang H, Wang F, Chu D, Zhang W, Liao Z, Fu Z, Yan X, Zhu H, Guo W, Zhang Y, et al: miR-93 functions as an oncomiR for the downregulation of PDCD4 in gastric carcinoma. Sci Rep 6: 23772, 2016.

35. Burris HA III, Moore MJ, Andersen J, Green MR, Rothenberg ML, Modiano MR, Cripps MC, Portenoy RK, Storniolo AM, Tarassoff $\mathrm{P}$, et al: Improvements in survival and clinical benefit with gemcitabine as first-line therapy for patients with advanced pancreas cancer: A randomized trial. J Clin Oncol 15: 2403-2413, 1997.

36. Ueno H, Ioka T, Ikeda M, Ohkawa S, Yanagimoto H, Boku N, Fukutomi A, Sugimori K, Baba H, Yamao K, et al: Randomized phase III study of gemcitabine plus S-1, S-1 alone, or gemcitabine alone in patients with locally advanced and metastatic pancreatic cancer in Japan and Taiwan: GEST study. J Clin Oncol 31: 1640-1648, 2013

37. Conroy T, Desseigne F, Ychou M, Bouché O, Guimbaud R, Bécouarn Y, Adenis A, Raoul JL, Gourgou-Bourgade S, de la Fouchardière $\mathrm{C}$, et al; Groupe Tumeurs Digestives of Unicancer; PRODIGE Intergroup: FOLFIRINOX versus gemcitabine for metastatic pancreatic cancer. N Engl J Med 364: 1817-1825, 2011.

38. Von Hoff DD, Ervin T, Arena FP, Chiorean EG, Infante J, Moore M, Seay T, Tjulandin SA, Ma WW, Saleh MN, et al: Increased survival in pancreatic cancer with nab-paclitaxel plus gemcitabine. N Engl J Med 369: 1691-1703, 2013.

39. Milross CG, Mason KA, Hunter NR, Chung WK, Peters LJ and Milas L: Relationship of mitotic arrest and apoptosis to antitumor effect of paclitaxel. J Natl Cancer Inst 88: 1308-1314, 1996.

40. Toyota Y, Iwama H, Kato K, Tani J, Katsura A, Miyata M, Fujiwara S, Fujita K, Sakamoto T, Fujimori T, et al: Mechanism of gemcitabine-induced suppression of human cholangiocellular carcinoma cell growth. Int J Oncol 47: 1293-1302, 2015. 